\title{
OPTIMIZING STOICHIOMETRIC WELDING FLUXES USING NeSTED RANDOM MODEL
}

\author{
ACHEBO, J. I.
}

Abstract: This research is aimed at developing a novel approach for selecting an optimum flux combination from a collection of various flux combinations by applying the Nested Random Model, with the stoichiometric characteristics of each of the flux combinations and the desired physical properties taken into consideration. Having been grouped into five batches, each specimen was used to make weld deposits and thereafter machined to determining their Ultimate Tensile Strength (UTS). The average UTS values were applied to the Nested Random Model, and Batch 1 was singled out for further analysis. The UTS of the weld deposit was thereafter subjected to Analysis of Variance (ANOVA), and the specimen which had the highest contribution, designated as fluxl $\left(45 \% \mathrm{NaCl}-45 \% \mathrm{CaCl}_{2}-2 \% \mathrm{CaF}_{2}-8 \% 3 \mathrm{NaFAlF}_{3}\right)$ was chosen. The Nested Random Model has been successfully adapted for the development of an optimum flux composition.

Key words: aluminum welding flux, nested random model, stoichiometric, ultimate tensile strength
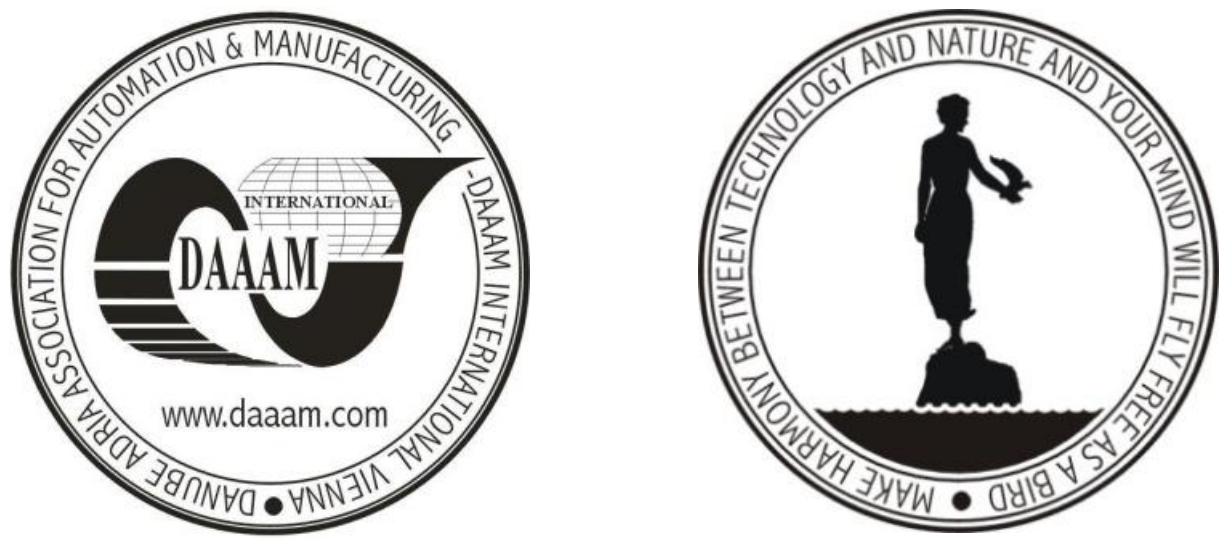

Authors' data: Dr. Achebo, J[oseph] [I.], Department of Production Engineering, Faculty of Engineering University of Benin, Benin City, Nigeria, josephachebo@yahoo.co.uk

This Publication has to be referred as: Achebo, J[oseph] [I.] (2010). Optimizing Stoichiometric Welding Fluxes Using Nested Random Model, Chapter 36 in DAAAM International Scientific Book 2010, pp. 377-394, B. Katalinic (Ed.), Published by DAAAM International, ISBN 978-3-901509-74-2, ISSN 1726-9687, Vienna, Austria

DOI: $10.2507 /$ daaam.scibook.2010.36 


\section{Introduction}

Aluminum alloys are light weight metals which tend to easily react with atmospheric oxygen to form a thin, hard, and tenacious layer of aluminum oxide $\left(\mathrm{Al}_{2} \mathrm{O}_{3}\right)$ on its surface. This thin oxide layer requires a very high temperature to melt (at about approximately $2050^{\circ} \mathrm{C}$ when compared to about $660^{\circ} \mathrm{C}$ needed to melt pure aluminum). During the welding process, aluminum oxides are inevitably introduced into the weld pool. Molten aluminum, as a result of its stiochiometric character, and the added presence of its oxide layer, absorbs any available hydrogen gas and has the ability to oxidize readily. The continuous deposition of the oxide layer in the weld pool occurs in the process of oxidizing and re-oxidizing during the welding process. Gas entrapment invariably occurs in the weld during solidification. This gas entrapment creates micron sized voids which in turn make the finished weld metal brittle. The oxide layer is thus an impediment to achieving a high quality weld and its effects can be stoichiometrically addressed with the introduction of a flux. A flux is an inorganic material which is a combination of Chlorides and Fluorides and other substances, used to prevent oxide contamination of the weld pool, fluxes also aid with the removal of impurities. They do this by forming a protective slag or dross during the weld process which rises to the surface of the molten metal. The British Standards Institute defines a slag as a fused, non metallic residue produced from certain welding processes (British Standards, 1965; Jackson, 1973).

In flux-metal reactions, a slag is the product formed after the reaction of a fused liquid flux with molten weld metal. Fluxes and their slag provide a blanket to protect the weld metal from the action of extraneous gases. The slag cover is a brittle, glasslike material which protects the weld until it cools. It actually detaches itself completely from the weld. This slag covers and protects the molten metal from external harm and leaves the weld bead with a smooth surface upon its removal (which unlike the oxide layer, does not form a tenacious bond with the cooled and solidified weld surface and can therefore be easily removed). An ideal slag is ductile at high temperatureswhich prevent oxidation of the weld metal and brittle at room temperature to facilitate slag removal (Jackson, 1973, Natalie et al, 1986).

The stoichiometric interaction is pretty straight forward. Slag solidifies at a relatively slow rate, it holds the heat and allows the underlying metal to cool and slowly solidify. The slow solidification of the metal eliminates the entrapment of any gas within the weld and permits solid impurities to float to the surface. Slow cooling also has an annealing effect on the weld deposit. The weld puddle, when in its highly liquid state is turbulent. For this reason, any slag or gas bubbles in the molten weld are quickly swept to the surface. The welding flux completely shields the welding zone from contact with the atmosphere. The flux is burnt by the heat of the flame; the smoke produced thereof acts as deoxidizer which protects the weld puddle from contact with the environment. A small amount of the flux can cause fusion to occur.

A welding flux could be applied by pouring it over the weld pool in a granular form as in submerged arc welding process, it can also be coated on the exterior of the 
bare electrode as is the case of shielded arc welding or the flux could be placed in the interior core of the electrode as is the case of flux core arc welding.

The extent to which welding fluxes affect molten aluminum depends on the stoichiometry of the applied flux material, morphology of the flux, amount of flux used for welding, the welding temperature, and contact time. Different fluxes have different properties such as fluidity, density, wet ability and reactivity, depending on the desired results. Chhibber \& Kaushal (2004) said that the physiochemical properties of the fluxes are the size mix, bulk density, flow ability, hygroscopic nature, melting point, melting range, surface tension, viscosity, current carrying capacity, welding speed and electrical conductivity. These properties, they said significantly affect the welding behavior of fluxes.

Aluminum fluxes are made of chloride and fluoride salts, Chloride salts are ionic and semi conductive (Marya \& Edwards, 2002), and possess a high fluidity effect in cleansing molten aluminum by destroying the thin oxide layer. They however do not significantly react or affect surface tension. On the other hand, fluorides salts have limited solubility of oxides, and therefore would not dissolve a large amount of aluminum. They however act as surfactants affecting surface tension forces between flux, liquid metal and aluminum oxides. As the flux wets the interface between the aluminum oxide particles and the liquid metal, the adhesion forces between the liquid aluminum and the oxide decreases, separating the oxide from aluminum and aiding the metal to coalesce. Fluorides are regarded as the most effective compounds used in fluxes to improve the recovery of lost metal from wet slag. This claim was supported by the study done by Ito et al. (1976). Ito et al. (1976) observed that oxygen content of submerged weld metal decreases with increasing $\mathrm{CaF}_{2}$ content of the flux. Chhibber \& Kaushal (2004) said that to attain the desired viscosity of coating, $\mathrm{CaF}_{2}, \mathrm{CaO}, \mathrm{MnO}$ and $\mathrm{TiO}_{2}$ could be added. Ferrera \& Olson (1975) were of the opinion that $\mathrm{CaO}$ or $\mathrm{CaF}_{2}$ addition to manganese silicate flux improves arc stability.

Marya\& Edwards (2002) said that a suitable flux must change weld dimensions with uniformity and repeatability. They also observed that as regards the application of the flux, it must be applied uniformly as differences in flux thickness may lead to an irregular weld bead with deteriorated properties. Chhibber \& Kaushal (2004) said that a flux stabilizes the arc by providing easily ionized elements as source of electrons and ions which sustain the arc.

But how is such a flux combination that satisfies the desired standards produced? The choice of an optimum flux composition is rather difficult to achieve (Achebo \& Ibhadode, 2008; 2009). This has lead to the formulation of different flux compositions depending on the mechanical properties any manufacturers may desire. Mohan (2009) was of the opinion that flux plays an important role in determining the weld metal quality. Chai \& Edgar (1981) said that the improvements in the flux and electrode compositions have resulted in weld metals possessing excellent properties but also observed that flux development for submerged arc and other weld processes has been approached empirically leaving a limited foundation upon which to base future progress. Chai \& Edgar (1981) in their study mentioned that a major advancement in systemizing the study of weld fluxes begun by Christensen \& 
Chipman (1953). Thereafter, other investigators (Kubli \& Sharav, 1961; Belton et al, 1963; Lewis et al, 1961; Christensen, 1965; Butler \& Jackson, 1967; North et al, 1978; North, 1977), did their various studies on submerged arc welding fluxes. They went further to note that several theories have been proposed to explain the observed trends in welding fluxes by Palm (1972); Boniszewsky (1974); Edgar (1978); Korth (1977); and Their (1980). However, these researches and conflicting conclusions, according to Chai \& Edgar, has left the field of welding fluxes stunted. This claim has also been made by Jackson (1973) that not enough research has been done in this field; therefore there is little research to this effect.

Several theories and models have been used for the formulation of fluxes which include the chemical composition based on the Hadamard Multivariate analysis (Achebo \& Ibhadode, 2008), the Statistical model based on the Expert Evaluation method (Achebo, 2009) and the Taguchi method. New optimization models are expected to be developed to further formulate flux compositions and enhance the field of aluminum welding thereby consistently producing welds with better quality and mechanical properties. The aim of this research is to apply the Nested Random Model to the discovery of an optimum aluminum flux.

In this study, various combinations of fluxes were formulated using the Hadamard Multivariate analysis, and broken down into three batches of five specimens each, and each was used to make weld deposits which were prepared and tested for their Ultimate Tensile Strength (UTS). The Nested Random Model was applied to select the flux combination that had the best contribution relative to their mechanical properties, batch by batch, until the best batch and the best specimen within that batch was discovered. This best performing flux combination, once discovered, was chosen as the optimum flux combination.

\section{Functions of Fluxes}

\subsection{Flux Inducing Low Melting Temperature}

Fluoride and chloride ions have very high melting points, i.e, they have high resistance to the intense arc heat that would not melt the flux material easily because of its fluoride ion contents and to a lesser extent chloride ions, therefore these ions reduce the effect of the arc heat on the weld metal, that is, as an ingredient in the flux material, when heated the flux ions tends to shield the hot gas flame from the weld material As a result of this the fluoride based flux reduces the effect of the high temperature from the arc on the weld puddle thereby inducing a low melting temperature of the filler metal and the contacting surfaces to be welded (it is the reduced temperature of the arc that heats or melts the filler metal and the contacting surfaces; this is the reason why a high temperature from the arc heat induces a low melting point).

\subsection{Fluxes as Arc Stabilizers}

The heated flux covering which produces the shielding gas contains both positive and negative ions, which increases the ionization content of the arc thereby stabilizing the arc to sustain the welding length and cycles. 
Welding arc here represents a concentrated high intense heat which contains localized ions (anions and cations) that would sustain the thermal cycle during the period of the welding process. A continuous flow of these ionized gases stabilizes the welding arc during the welding cycle and the continuous feeding of electrons into the welding area from the shielding gas accounts for the continuing balance between electrons and ions in the arc. The electrons colliding with the work create the intense localized heat which provides melting and deep penetration of the base metal.

\subsection{Fluxes as a Form of Shielding}

When flux decomposes as heat is applied, it forms a smoke which spreads around the welding area. This smoke prevents the weld area from contact with the environment. This smoke also called oxygen scavengers, absorbs the oxygen within the work area. The smoke is a combination of chloride gas and to a lesser extent fluoride gas. This gas shields the molten weld from the environment.

Utigard et al (1998) are of the opinion that the flux produces the reducing gas shield around the arc which prevents atmospheric oxygen or nitrogen from contaminating the weld metal. Oxygen readily combines with the molten metal, removing alloying elements and could thereby cause porosity. Nitrogen causes brittleness, low ductility, and in some cases, low strength and poor resistance to corrosion.

\subsection{Fluxes as an Alloying Element}

When heat is applied to flux material, major elements like $\mathrm{Ca}^{2+}$ and $\mathrm{Na}^{+}$ interact with the molten metal and add to the chemical composition of the weld metal. These elements are alloyed with the weld metal. These alloying elements alter the mechanical properties of aluminum in a positive way. They could increase the strength of the material. However, on the other hand the presence of these alloying elements reduces the corrosion resistance of the aluminum product (Utigard et al, 1998).

\subsection{Fluxes as a Demaging Agent}

Demaging is the removal or reduction of magnesium contents in aluminum alloy. The barrier of aluminum oxide on the metal surface resists hydrogen pick up, therefore, disturbances of the surface that break the oxide barrier result in rapid hydrogen dissolution. However, aluminum alloying elements such as magnesium which has a very high affinity for oxygen may increase hydrogen absorption by forming oxide products that lead to reduced resistance to the diffusion of hydrogen into the melt (Utigard et al, 1998). One type of the demaging process is chlorination; this is the use of solid chloride containing fluxes, and the injection of AIF, or $\mathrm{NaAlF}_{4}$ compounds (Utigard et al, 1998). Chlorides are the flux ingredients that are used to effectively reduce magnesium in aluminum alloys.

\section{Factors Influencing Flux Performance}

The factors influencing flux performance are as follows: 


\subsection{Temperature: Coefficient of Expansion}

The temperature coefficient of expansion of the slag is vastly different from that of the base material because the slag materials are very light weight, being oxidized flux materials that have floated from within the weld pool to the top weld pool during cooling. This upward movement is as a result of the density difference between the viscoplastic weld pool and the very fluid and light weight slag material. Only a simple marginal difference between the coefficient of expansion of the weld pool and that of the slag is required to give good slag removal. It must also be noted that slag lifting which occurs too rapidly may result in undesirable temper colors of the weld bead. The friability and temperature coefficient of expansion of the slag can be controlled by carefully manipulating the stoichiometric composition of the slag and by adding minerals known to have a coefficient of expansion different from that of the base material (Jackson, 1973). Natalie et al (1986) suggested that the retention of the slag layer on the weld metal may reduce the corrosion resistance of the weld metal. Retaining this slag may also promote slag stringers in multipass welding and generally impair the appearance of the weldment.

\subsection{Flux Viscosity}

Utilizing the appropriate viscosity of welding fluxes is vital because a flux must be fluid enough to permit evolution of gases and to allow for rapid solution to oxide inclusions (Natelie et al,1986). Also, a welding flux must have a viscosity high enough to protect the metal from atmospheric gases, prevent the pitting of weld beads, and to support the weld pool (Natelie et al,1986), by preventing it from floating away from the weld pool. However, the viscosity should be low enough to allow gases to be evolved from the molten metal. This becomes necessary since the slag shapes the weld bead (Jackson, 1973). By constraining and directing the flow of molten metal, the flux concentrates the heat in a small area and directs the fluid flow to the deepest parts of the gaps of the specimen to be welded, thereby achieving adequate weld penetration.

Natelie et al,(1986) said that the ability of a flux to refine and protect the weld pool is related to the mass transport process in the flux. For proper flux coverage, the flux should melt at a temperature approximately $200^{\circ} \mathrm{C}$ below that at which the alloy melts. It should be sufficiently viscous to hinder oxygen transportation through the flux to the weld pool during the extremely fast thermal cycling of the welding process. This is because high temperatures or a thermal environment would attract a high moisture influx into the weld pool. The viscosity of welding fluxes depends on temperature. As the temperature increases, viscosity decreases, i.e. the flux becomes more fluid.

\subsection{Surface Tension}

Surface forces affect the transfer of liquid metal across an arc. Marya\& Edwards (2002) defined the welding arc as a sustained discharged plasma with a highly non uniform electric potential. Marya\& Edwards (2002) cited Jackson (1960) and Lancaster (1984) that the arc is separated into three regions: cathode, anode and the arc column. Gaseous particles within these regions originate from the shielding 
gas, the ambient air, and the vaporization of the flux, the base metal, and to a lesser extent, the electrode. Liquid metal transfer modes could be transported by lowering the surface tension, increasing the plasma jet environment, and this would propel a gravity induced flow when considering welding in flat position.

Surface tension of a liquid metal at the tip of the electrode between the arc and the gap between the work pieces causes the surface of the liquid to contract to the smallest possible area on the electrode tip. This tension tends to hold the liquid drops on the end of a melting electrode without regard to weld position. This force works against the transfer of metal across the arc and helps keep molten metal in the weld pool when welding in the over-head position.

When welding in a gaseous environment, the plasma produced by the constriction of the welding arc contains high speed ionic gases, which coupled with the intense heat emitted by the welding arc exerts very high pressure on the molten metal at the electrode tip, causing it to break or neck down by sliding gradually in accordance with the globular nature of the molten metal, one drop after the other. What happens is that there is a reduction in the surface tension force holding the molten metal to the electrode tip; this continues until the pressure or force exerted by the plasma jet completely overcomes the surface tension force holding the molten metal to the electrode tip. When welding in a flat position, the molten metal falls into the weldpool by gravity.

Gravity detaches the liquid drop when the electrode is pointed downward; it is also a restraining force when the electrode is pointing upward. The difference between the mass of the molten metal droplets and the mass of the work piece has a gravitational effect which tends to pull the droplet to the work piece. Jackson (1973) was of the opinion that surface tension should be low so that the slag can coalesce into large particles and thus rise rapidly to the surface of the molten metal. Natelie et al (1986) observed that the interfacial tension between the molten flux and the weld and parent metal has been found to be a function of flux composition.

\section{Methodology}

The methodology illustrates a step by step application of the Nested Random Model (Diamond, 1989) using the UTS results obtained from laboratory test results. The nested design allows few variables in all levels of one factor to occur within each level of the other factors. The levels of a factor are considered to be random such that all the levels in the experimental design are selected at random from a large number of possible levels. This model becomes a nested random model. This model is used to analyze and interpret a component of variance. The various flux combinations were randomly selected and broken down into three batches of five specimens each. Each specimen within each group was thereafter used to make weld deposits. These weld deposits were further machined into individual specimens for testing, investigating and determining their Ultimate Tensile Strength (UTS), being a vital mechanical property of each of these specimens. The average UTS values were applied to the Nested Random Model to determine, stoichiometrically, which batch would most 
Achebo, J. I.: Optimizing Stoichiometric Welding Fluxes Using Nested Random ...

likely have the ultimate flux combination, this being based on the quality of the weld as well as the ductility of the weld material.

The flux combinations that were grouped in three batches, their UTS results are shown in Tables $1-3$. And the chemical compositions of the fluxes are itemized in Table 4. The procedure is demonstrated here under.

Batch 1

\begin{tabular}{|l|l|l|l|l|l|}
\hline Test run & 1 & 2 & 3 & 4 & Total \\
\hline Flux 1 & 255 & 275 & 310 & 243 & 1083 \\
\hline Flux 2 & 323 & 276 & 299 & 264 & 1162 \\
\hline Flux 3 & 306 & 334 & 316 & 330 & 1286 \\
\hline Flux 4 & 314 & 323 & 306 & 294 & 1237 \\
\hline Flux 5 & 309 & 289 & 316 & 307 & 1221 \\
\hline Total & 1507 & 1497 & 1547 & 1438 & \\
\hline
\end{tabular}

Tab.1. Flux combinations in batch one (UTS, MPa Result)

Batch 2

\begin{tabular}{|l|l|l|l|l|l|}
\hline Test run & 1 & 2 & 3 & 4 & Total \\
\hline Flux 1 & 278 & 324 & 297 & 289 & 1188 \\
\hline Flux 2 & 316 & 296 & 276 & 306 & 1194 \\
\hline Flux 3 & 309 & 326 & 305 & 220 & 1160 \\
\hline Flux 4 & 302 & 323 & 282 & 246 & 1153 \\
\hline Flux 5 & 273 & 289 & 309 & 310 & 1181 \\
\hline Total & 1478 & 1558 & 1469 & 1371 & \\
\hline
\end{tabular}

Tab. 2. Flux combinations in batch two (UTS, MPa Result)

Batch 3

\begin{tabular}{|l|l|l|l|l|l|}
\hline Test run & 1 & 2 & 3 & 4 & Total \\
\hline Flux 1 & 315 & 291 & 305 & 268 & 1179 \\
\hline Flux 2 & 311 & 281 & 292 & 310 & 1194 \\
\hline Flux 3 & 279 & 265 & 289 & 305 & 1138 \\
\hline Flux 4 & 305 & 296 & 306 & 243 & 1150 \\
\hline Flux 5 & 261 & 317 & 298 & 306 & 1182 \\
\hline Total & 1471 & 1450 & 1490 & 1432 & \\
\hline
\end{tabular}

Tab. 3. Flux combinations in batch two (UTS, MPa Result) 


\begin{tabular}{|l|l|l|l|l|}
\hline Flux No. & $\begin{array}{l}\mathrm{NaCl} \\
\% \text { by weight }\end{array}$ & $\begin{array}{l}\mathrm{CaCl}_{2} \\
\% \text { by weight }\end{array}$ & $\begin{array}{l}\text { CaF } \\
\% \text { by weight }\end{array}$ & $\begin{array}{l}\text { 3 NaFAlF } \\
\% \text { by weiğht }\end{array}$ \\
\hline 1 & 45 & 45 & 2 & 8 \\
\hline 2 & 50 & 44 & 2 & 4 \\
\hline 3 & 45 & 41 & 6 & 8 \\
\hline 4 & 49 & 45 & 2 & 4 \\
\hline 5 & 46 & 40 & 6 & 8 \\
\hline
\end{tabular}

Tab. 4. Chemical composition of the fluxes used

Sum of squares within each Batch within each flux type

Computing the test sum of squares for each batch

$$
S S_{0}=\frac{\sum X_{i}^{2}}{N_{1}}-\frac{\left(\sum X_{i}\right)^{2}}{N_{2}}
$$

In each batch, there are four test results, therefore, for $\mathrm{SS}_{\mathrm{o}}, \mathrm{N}_{2}=4$ and $\mathrm{N}_{1}=1$. The number of degree of freedom on each group is $\mathrm{n}_{\text {test }}-1=4-1=3$ degree of freedom $(d f)$

\section{Batch 1}

For Flux 1

Applying Eq(1), we have

$S S_{0}=(255)^{2}+(275)^{2}+(310)^{2}+(243)^{2}-\frac{(255+275+310+243)^{2}}{4}$

$=2576.75=\mathrm{SS}_{0}$ with $3 \mathrm{df}$

For Flux 2

$S S_{0}=(323)^{2}+(276)^{2}+(299)^{2}+(264)^{2}-\frac{(323+276+299+264)^{2}}{4}$

$=2041=\mathrm{SS}_{0}$ with $3 \mathrm{df}$

For Flux 3

$S S_{0}=(306)^{2}+(334)^{2}+(316)^{2}+(330)^{2}-\frac{(306+334+316+330)^{2}}{4}$

$=499=\mathrm{SS}_{0}$ with $3 \mathrm{df}$

For Flux 4

$S S_{0}=(314)^{2}+(323)^{2}+(306)^{2}+(294)^{2}-\frac{(314+323+306+294)^{2}}{4}$

$=454.75=\mathrm{SS}_{0}$ with $3 \mathrm{df}$ 


\section{For Flux 5}

$S S_{0}=(309)^{2}+(289)^{2}+(316)^{2}+(307)^{2}-\frac{(309+289+316+307)^{2}}{4}$

$=396.75=\mathrm{SS}_{0}$ with $3 \mathrm{df}$

\section{Batch 2}

\section{For Flux 1}

$S S_{0}=(278)^{2}+(324)^{2}+(297)^{2}+(289)^{2}-\frac{(278+324+297+289)^{2}}{4}$

$=1154=\mathrm{SS}_{0}$ with $3 \mathrm{df}$

For Flux 2

$S S_{0}=(316)^{2}+(296)^{2}+(276)^{2}+(306)^{2}-\frac{(316+296+276+306)^{2}}{4}$

$=875=\mathrm{SS}_{0}$ with $3 \mathrm{df}$

For Flux 3

$S S_{0}=(309)^{2}+(326)^{2}+(305)^{2}+(220)^{2}-\frac{(309+326+305+220)^{2}}{4}$

$=6782=\mathrm{SS}_{0}$ with $3 \mathrm{df}$

For Flux 4

$S S_{0}=(302)^{2}+(323)^{2}+(282)^{2}+(246)^{2}-\frac{(302+323+282+246)^{2}}{4}$

$=3220.75=\mathrm{SS}_{0}$ with $3 \mathrm{df}$

For Flux 5

$S S_{0}=(273)^{2}+(289)^{2}+(309)^{2}+(310)^{2}-\frac{(273+289+309+310)^{2}}{4}$

$=940.75=\mathrm{SS}_{0}$ with $3 \mathrm{df}$

Batch 3

For Flux 1

$S S_{0}=(315)^{2}+(291)^{2}+(305)^{2}+(268)^{2}-\frac{(315+291+305+268)^{2}}{4}$

$=1244.75=\mathrm{SS}_{0}$ with $3 \mathrm{df}$

For Flux 2

$S S_{0}=(311)^{2}+(281)^{2}+(291)^{2}+(310)^{2}-\frac{(311+281+292+310)^{2}}{4}$

$=637=\mathrm{SS}_{0}$ with $3 \mathrm{df}$ 
For Flux 3

$S S_{0}=(279)^{2}+(265)^{2}+(289)^{2}+(305)^{2}-\frac{(279+265+289+305)^{2}}{4}$

$=851=\mathrm{SS}_{0}$ with $3 \mathrm{df}$

For Flux 4

$S S_{0}=(305)^{2}+(296)^{2}+(306)^{2}+(243)^{2}-\frac{(305+296+306+243)^{2}}{4}$

$=2701=\mathrm{SS}_{0}$ with $3 \mathrm{df}$

For Flux 5

$S S_{0}=(261)^{2}+(317)^{2}+(298)^{2}+(306)^{2}-\frac{(261+317+298+306)^{2}}{4}$

$=1769=\mathrm{SS}_{0}$ with $3 \mathrm{df}$

\begin{tabular}{|l|l|l|l|l|}
\hline Flux & Batch 1 & Batch 2 & Batch 3 & Total \\
\hline 1 & $S S_{0}=2576.75$ & 1154 & 1244.75 & 4975.5 \\
\hline 2 & $S S_{0}=2041$ & 875 & 637 & 3553 \\
\hline 3 & $S S_{0}=499$ & 6782 & 851 & 8132 \\
\hline 4 & $S S_{0}=454.75$ & 3220.75 & 2701 & 6376.5 \\
\hline 5 & $S S_{0}=396.75$ & 940.75 & 1769 & 3106.5 \\
\hline & & & & 26143.5 \\
\hline
\end{tabular}

Tab. 5. Computation results on the test runs

$\sum S S_{0}=26143.5$ with $45 \mathrm{df}$

$M S_{0}=\frac{26143.5}{45}=580.97$

Retrieving and pasting the totals of the columns in tables 1, 2, and 3. Summarily a two way chart of Batch vs Group is formed as presented in Table 6

\begin{tabular}{|l|l|l|l|l|}
\hline Flux & Batch 1 & Batch 2 & Batch 3 & Total \\
\hline 1 & 1083 & 1188 & 1176 & 3450 \\
\hline 2 & 1162 & 1194 & 1194 & 3550 \\
\hline 3 & 1286 & 1160 & 1138 & 3584 \\
\hline 4 & 1237 & 1153 & 1150 & 3540 \\
\hline 5 & 1221 & 1181 & 1182 & 3584 \\
\hline Total & 5989 & 5876 & 5843 & 17708 \\
\hline
\end{tabular}

Tab. 6. Two way chart of flux vs Batch 
The variations between batches within fluxes and the variations fluxes are obtained by making up a two way chart of Flux vs Batch (see Table 7)

Sum squares due to Batches

On each flux the sum of squares due to batches is computed by using Eq.(1). Each factor, $X_{i}$ however, at this stage, is the sum of the four test results in a given batch within a given flux.

Therefore $\mathrm{N}_{1}=4, \mathrm{~N}_{2}=3 \times 4=12$. The degree of freedom (df) is the numbers of groups minus one, i.e., $3-1=2 \mathrm{df}$

Therefore $\mathrm{SS}_{1}$ for flux 1 is

$S S_{1}=(1083)^{2}+(1188)^{2}+(1179)^{2}-\frac{(3450)^{2}}{3 \times 4}$

$=2982399=\mathrm{SS}_{1}$ with $2 \mathrm{df}$

For Flux 2

$S S_{1}=(1162)^{2}+(1194)^{2}+(1194)^{2}-\frac{(3550)^{2}}{3 \times 4}$

$=3151307.67=\mathrm{SS}_{1}$ with $2 \mathrm{df}$

For Flux 3

$S S_{1}=(1286)^{2}+(1160)^{2}+(1138)^{2}-\frac{(3584)^{2}}{3 \times 4}$

$=3224018.67=\mathrm{SS}_{1}$ with $2 \mathrm{df}$

For Flux 4

$S S_{1}=(1237)^{2}+(1153)^{2}+(1150)^{2}-\frac{(3540)^{2}}{3 \times 4}$

$=3137778=$ SS $_{1}$ with $2 \mathrm{df}$

For Flux 5

$S S_{1}=(1221)^{2}+(1181)^{2}+(1182)^{2}-\frac{(3584)^{2}}{3 \times 4}$

$=3212304.67=\mathrm{SS}_{1}$ with $2 \mathrm{df}$

$\sum S S_{1}=2982399+3151307.67+3224018.67+3137778+3212304.67$

$=15707808.01$ with $10 \mathrm{df}$

(i.e. $2+2+2+2+2=10 \mathrm{df}$ )

$M S=\frac{\sum S S_{1}}{d f}=\frac{15707808.01}{10}=1570780.80$ 
Sum of squares between fluxes

The sum of square between fluxes is computed by the same formula given in $\mathrm{Eq}(1)$.

Each factor, $x_{i}$, is the sum of the four test results on the three batches made with a flux combination. Therefore $\mathrm{N}_{1}=12$ and $\mathrm{N}_{2}=12 \times 5=60$; $\mathrm{df}$ is the number of fluxes minus one, i.e., $5-1=4 \mathrm{df}$

From the totals recorded in Table 6

$S S_{2}=\frac{(3450)^{2}+(3550)^{2}+(3584)^{2}+(3540)^{2}(3584)^{2}}{12}-\frac{(17708)^{2}}{60}$

$=1004.93$ with $4 \mathrm{df}$

$M S_{2}=\frac{1004.93}{4}=251.23$

A variance component table is constructed from the generated data

\begin{tabular}{|l|l|l|l|l|}
\hline Source of Variance & df & $\begin{array}{l}\text { sum of } \\
\text { square }\end{array}$ & $\begin{array}{l}\text { mean } \\
\text { square }\end{array}$ & $\begin{array}{l}\text { variance } \\
\text { estimated by } \\
\text { mean square }\end{array}$ \\
\hline Between Fluxes & 4 & 1004.93 & 251.23 & $\sigma_{0}^{2}+4 \sigma_{1}^{2}+12 \sigma_{2}^{2}$ \\
\hline $\begin{array}{l}\text { Between Batches } \\
\text { within fluxes }\end{array}$ & 10 & 15707808.01 & 1570780.80 & $\sigma_{0}^{2}+4 \sigma_{1}^{2}$ \\
\hline $\begin{array}{l}\text { Between Test } \\
\text { results within } \\
\text { Batches }\end{array}$ & 45 & 26143.5 & 580.97 & $\sigma_{0}^{2}$ \\
\hline
\end{tabular}

Tab. 7. A variance component table

In this study, $\sigma_{0}=S=$ variance

From Table 6

$S_{0}^{2}+4 S_{1}^{2}=1570780.80$

And $S_{0}^{2}=580.97$

$\therefore S_{1}^{2}=\frac{1570780.80-580.97}{4}$

$=392549.96$

$S_{0}^{2}+4 \sigma_{1}^{2}+12 S_{2}^{2}=1570780.80+12 S_{2}^{2}$

$S_{2}^{2}=-\frac{-1570780.80}{12}=-130898.4$ 


\section{Results}

\subsection{Interpretation of Applied Model Results}

1. There is a large variation in the test variance of the Ultimate Tensile Strength (UTS) values $\left(\mathrm{S}_{0}{ }^{2}=580.97\right)$ within the flux combinations. This value explains the reason why there are different results of UTS obtained. Because of the large variation in the results, this procedure would then be applied to a single procedural approach, which is expressed as $\pm t_{\alpha} S= \pm(2.02)(24.10)=48.69$ with $95 \%$ confidence level, this means that from the probability point of t-distribution, single sided factor is considered when $\sigma^{2}=\mathrm{S}^{2}$ is unknown, $\mathrm{t}_{\alpha=0.05,5}=2.02$ and $S_{0}=\sqrt{580.97}=24.10$. If we assume a precision value of \pm 24 with $95 \%$ confidence is desired for a given combination of flux treatment considering the deviation of the UTS results from the mean. The acceptable number of test runs that is expected to be conducted would be $\frac{t_{\alpha} S}{\sqrt{N}}=24$. Therefore, $N=\left[\frac{t_{\alpha} S}{24}\right]^{2}=\left[\frac{(2.02)(24.10)}{24}\right]^{2}=4.11$. This result for $\mathrm{N}$ indicates that four test runs is appropriate for this research project.

2. The sampling variance value of $S_{1}^{2}=392549.96$ is higher than the test variance. This indicates either lack of homogeneity within a batch or variation in the sample making procedure. Therefore, it is advised to make one batch of flux combinations.

3. Here, there appears to be proper collation of results within a batch which could be attributed to improved technology $\left(S_{2}^{2}=-130898.4\right)$. To further buttress this argument, the confidence level of procedural efficiency is measured when $(1-\alpha)$, for flux combinations confidence $= \pm\left[\frac{S_{1}^{2}}{n}+\frac{S_{0}}{k n}\right]^{\frac{1}{2}}$, where $\mathrm{n}$ in this case is the number of batches and $\mathrm{k}$ is the number of test runs $\pm 2.02\left[\frac{392549.96}{3}+\frac{580.97}{3 \times 4}\right]^{\frac{1}{2}}= \pm 730.83$. This shows that the accuracy of the testing procedure for a batch is not accurate at $95 \%$ confidence interval and this could result in large error occurring or could be as a result of laboratory test operator's bias.

\subsection{Discussion of Result}

From the analysis based on the interpretation of results, it is found that Flux combinations in batch 1 make up the most appropriate batch suitable for further investigation using this model because batch 2 showed a large sample variance and batch 3 is prone to error due to inaccurate test procedures.

From the discussion of the results, we therefore need to recall Table 1 for further investigations. 
The next stage here is to determine the ANOVA of the UTS results of the Flux combinations in Table 1 using the equation proposed by Berginc et al (2006) to determine the sum of squares as expressed in Eqs (2) and (3).

$$
\begin{gathered}
S S_{1}=\sum_{i=1}^{N} y_{i}^{2}-C F \\
C F=\frac{T^{2}}{N}
\end{gathered}
$$

Where

$\mathrm{T}=$ the sum of all results

$\mathrm{N}=$ the number of results

$\mathrm{CF}=$ correction factor

Scheaffer \& McClave (1982) proposed Eqs (4) - (6) for determining the total sum of squares (TSS) and sum of square errors (SSE).

$$
\begin{gathered}
S S E=T S S-S S T=\sum_{i=1}^{N}\left(y_{i}-\bar{y}\right)^{2} \\
T S S=\sum y^{2}-\frac{\left(\sum y\right)^{2}}{N} \\
S S T=\sum_{i=1}^{5} \frac{T_{i}^{2}}{N_{i}}-\frac{\left(\sum y\right)^{2}}{N}
\end{gathered}
$$

and

The ANOVA table is presented in Table 8

\begin{tabular}{|l|l|l|l|l|l|}
\hline $\begin{array}{l}\text { Flux } \\
\text { Combination }\end{array}$ & $\begin{array}{l}\text { Degree of } \\
\text { Freedom }\end{array}$ & Sum of Square & Variance & F-ratio & $\begin{array}{l}\text { Contribution } \\
\text { Percent }\end{array}$ \\
\hline Flux 1 & 3 & 2576.75 & 859 & 21475 & 43.17 \\
\hline Flux 2 & 3 & 2041 & 680 & 17000 & 34.19 \\
\hline Flux 3 & 3 & 499 & 166 & 4150 & 8.36 \\
\hline Flux 4 & 3 & 455 & 152 & 3860 & 7.62 \\
\hline Flux 5 & 3 & 397 & 132 & 3300 & 6.65 \\
\hline Error & 6 & 0.25 & 0.04 & - & 0.004 \\
\hline Total & 21 & 5969 & - & - & 100 \\
\hline
\end{tabular}

Tab. 8. ANOVA table 
From the result of the ANOVA in Table 8, the F-test at 95\% confidence level shows that at higher $\mathrm{F}$ values, the variation in the flux combinations within the batch under consideration makes a significant impact on performance. From Table 8, Flux 1 has a percent contribution of $43.17 \%$, Flux 2 has its percent contribution as $34.19 \%$, but Flux 3 has a percent contribution of $8.36 \%$, Flux 4 with a percent contribution of $7.62 \%$ and Flux 5 being $6.65 \%$.

The percent contribution indicates the ability of a flux combination to reduce variation. Therefore, Flux 1 stands out as the most effective flux combination, followed closely by Flux 2 . The other three flux combinations are not as effective as either flux 1 or flux 2. Since Flux 1 is more effective than Flux 2. Flux 1 is therefore chosen as the optimum flux combination.

\section{Conclusion}

The various flux combinations had been mixed up in a random manner. Therefore there was no specific criterion for categorizing the flux materials into the batches. But the application of the model helped reduce the number of variables with two particular flux specimens in batch 1 emerging as the most promising flux combinations. From the analysis, these two flux combinations contributed very well to reducing variation in the weld property.

Either of these two fluxes is suitable. In this study however, where one flux combination must emerge as the optimum having the most percent contribution, Flux 1 was chosen. The Nested Random model has been successfully used to determine the optimum flux combination amongst various flux combinations based on their stoichiometric as well as physical properties, being their UTS.

This procedure can also be applied to determine an optimum composition from a series of other compositions in related areas of study.It must be noted that to apply this model researchers need a relatively large number of different fluxes. In other words it does not provide the means to arrive at these fluxes. The utility of model arises however, when the researcher needs to select the optimum flux from a large number of existing fluxes.

\section{Reference}

Achebo J.I \& Ibhadode, A.O.A. (2008). Development of a New Flux for Aluminum Gas Welding; Advanced Material Research, Vols. 44/46 (Trans Tech Publications, Switzerland). P. 677-684 
Achebo J.I. (2009). Development of Compositions of Aluminum Welding Fluxes, using Statistical Method. International Multi conference of Engineeers and computer Scientists, Hong Kong, 18-20 March, p. 1876

Achebo J.I \& Ibhadode, A.O.A. (2009). Determination of Optimum Welding Flux Composition Using the Bend Strength Test Technique; Advanced Material Research, Vols. 62/64 (Trans Tech Publications, Switzerland). P. 393-397.

Belton, G. R., Moore, T. J. \& Tankins, E.S.(1963) Slag Metal Reaction in Arc Welding, Welding Journal, Vol. 42, No. 7, p.289s-297s

Berginc, B; Kampus, Z \& Sustarsic, B. (2006). The Use of Taguchi Approach to Determine the Influence of Injection Moulding Parameters on the Properties of Green Parts, Journal of Achievements in Materials and Manufacturing Engineering, vol. 15, Issue 1-2, p. 66

Boniszewski, T. (1974). Basic Fluxes and Deoxidation in Submerged Arc Welding of Steel, Metal Constr. Brit. Weld. Journal, Vol. 6, p.128

Butler, C. A. \& Jackson, C. E. (1967). Submerged Arc Welding Characteristics of the $\mathrm{CaO}-\mathrm{TiO}_{2}-\mathrm{SiO}_{2}$ System, Welding Journal, Vol. 46, No. 5, p.445-448

Chai, C.S \& Eagar, T.W (1981) Slag-Metal Equilibrium during Submerged Arc Welding, Metall. Trans. B, Vol. 2B, P.539

Chhibber, R. \& Kanushal, G.C. (2004). Development of Coated Electrodes for welding of HSLA Steels, Int. Symposium of Research Students on Materials Science and Engineering, December 20-22, 2004; Chennai, India.

Christensen, N. \& Chipman, J. (1953). Slag-Metal Interaction in Arc Welding, Welding Research Council, Bulletin 15

Christensen, N. (1965). Spatial Distribution of Manganese, Silicon, Chromium and Oxygen in Submerged Arc Weld Deposits, Contract DA-91-591 EVC 3455, U.S Dept. of Army European Research Office, November

Diamond, W. J. (1989). Practical Experimental Design for Engineers and Scientists, $2^{\text {nd }}$ Ed. Van Nostrand Reinhold, New York, p.89 - 123, $296-306$

Eager, T.W. (1978). Source of Weld Metal Oxygen Contamination during Submerged Arc Welding, Welding Journal, Vol.57, No. 2, p.76s-80s

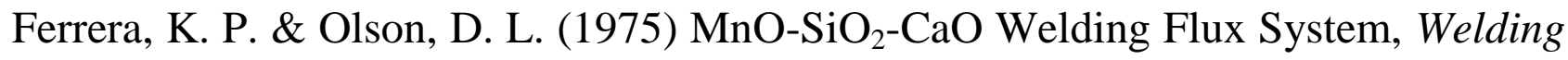
Journal, Vol. 54, No. 7, p.211s

Ito, Y; Nakaniski, M. \& Katsumoto, N. (1976). Effect of CaF2 on Roughness of Weld Metal. The Sumitomo Search 16; 78

Jackson, C.E. (1960). The Science of Arc Welding. Internal document of the Union Carbide Corporation, No. 52 - 501, also published in the Welding Journal with the following references, 39(4):129-s to 146-s, 39(5): 177-s to 190-s, 39(6): 225-s to $230-\mathrm{s}$

Jackson, C.E. (1973). 'Fluxes and Slags in Welding' Welding Research Council BulletinsNo.190, p.25-57

Korth, B. A. (1977). Thermodynamic Calculation of Alloying from the Slag and Deoxidation of Metal during Welding, Auto Weld., Vol.30, No. 7, p.16-21 
Kubli, R.A. \& Sharav, W.B. (1961). Advancement in Submerged Arc Welding of High Impact Steels, Welding Journal, Vol. 40, p.479s-507s

Lancaster, J. F. (1984). The Physics of Welding, Pergamon Press, USA p. 74 - 78

Lewis, W.I., Faulkner, G.E. \& Rieppel, P. I. (1961). Flux and Filler Wire Development for Submerged Arc Welding HY-80 Steel, Welding Journal, Vol. 40, No. 8, August, Research Supplement, p.337s

Marya, M \&Edwards, G. R. (2002). Chloride Contributions in Flux-Assisted GTA Welding of Magnesium Alloys, Welding Journal, p.291s - 298s

Monhan, N. (2009). Development of Cost Effective Agglomerate Fluxs from waste Flux Dust for Submereged Arc Welding Proc. of World Congress of Engineering. Vol. 1, July 1-3, London, UK

Natalie, C. A.; Olson, D. L. \& Blander, M. (1986). 'Physical and Chemical Behaviour of Welding Fluxes' Annual Review of Materials Science, Vol.16, p. $389-413$, August

North, T.H. (1977). The Distribution of Manganese between Slag and Metal Arc Welding The Welding Institute London, January, Vol. 23, No. 1, p.2

North, T.H., Bell, H.B., Nowicki, A. \& Craig, I. (1978). Slag/Metal Interaction, Oxygen and Toughness in Submerged Arc Welding, Welding Journal, Vol. 57, No. 3, p. 63s-75s

Palm, J.H. (1972). How Fluxes determine the Metallurgical Properties of Submerged Arc Welds, Welding Journal, Vol. 51, No. 7,p. 358s-360s

Scheaffer, R. L. \& McClave, J. T. (1982). Statistics for Engineers, Duxbury Press, Boston, p. $239-355$

Their, H. (1980). Metallurgical Reactions in Submerged Arc Welding, Paper 20, Proceedings of a Conference on Weldpool Chemistry and Metallurgy. The Welding Institute, London, April, p.271

Utigard, T. A.; Friesen, K,; Roy, R. R.; Lim, J.; Silny, A. \& Dupuis, C. (1998). 'The

Properties and Uses of Fluxes in Molten Aluminum Processing' JOM, November, p.38

Welding Terms \& Symbols Part 1, Welding, Brazing \& Thremal Cutting Glossary, British Standard 499, Part 1: 1965, British Standards Institution, London 